\title{
Experimental and numerical investigation of the single-point incremental forming of aluminium alloy foils
}

\author{
Imre Paniti ${ }^{1}$, Zsolt János Viharos ${ }^{1,2}$, Dóra Harangozó ${ }^{3}$, Sherwan Mohammed Najm ${ }^{4}$ \\ ${ }^{1}$ Institute for Computer Science and Control, H-1111 Budapest, Kende u. 13-17., Hungary \\ 2 John von Neumann University, H-6000, Izsáki str. 10, Kecskemét, Hungary \\ ${ }^{3}$ Széchenyi István University, H-9026 Györ, Egyetem tér 1., Hungary \\ ${ }^{4}$ Budapest University of Technology and Economics, H-1111 Budapest, Múegyetem rkp. 3., Hungary
}

\section{ABSTRACT}

Single-Point Incremental Forming (SPIF) is a flexible process for manufacturing sheet metal parts that is well adapted and profitable for prototypes or small batch production. Compared to traditional sheet forming technologies, this relatively slow process can be used in different applications in the automotive and aircraft industries; architecture engineering; and medical aid manufacture. In this article, the indirectly obtained axial forming force on the SPIF of variable wall angle geometry is studied using different process parameters. The estimation of the forces on AIMn1Mg1 sheets with an initial thickness of $0.22 \mathrm{~mm}$ is performed by continuous monitoring of servomotor currents. The deformation states of the formed parts were analysed using the ARGUS optical strain measurement system of GOM, while the roughness measurements were carried out by a Mitutoyo system. Some initial finite element analysis simulations and a crack monitoring method together with an interaction plot of forming speed, incremental depth, tool diameter, and lubrication were also reported.

\section{Section: RESEARCH PAPER}

Keywords: Incremental Sheet Forming; Crack Monitoring; Optical Strain Measurement; Design of Experiments

Citation: Imre Paniti, Zsolt J. Viharos, Dóra Harangozó, Sherwan M. Najm, Experimental and numerical investigation of the single-point incremental forming of aluminium alloy foils, Acta IMEKO, vol. 9, no. 1, article 5, March 2020, identifier: IMEKO-ACTA-9 (2020)-1-5

Editor: Lorenzo Ciani, University of Florence, Italy

Received November 5, 2019; In final form February 5, 2020; Published March 2020

Copyright: This is an open-access article distributed under the terms of the Creative Commons Attribution 3.0 License, which permits unrestricted use, distribution, and reproduction in any medium, provided the original author and source are credited.

Funding: This work was supported by H2020 project EPIC under grant No. 739592, ED_18-2-2018-0006 and EFOP-3.6.2-16-2017-00016 project grants.

Corresponding author: Imre Paniti, e-mail: imre.paniti@sztaki.hu

\section{INTRODUCTION}

Incremental sheet metal forming, with its main variants Single-Point Incremental Forming (SPIF) and Two-Point Incremental Forming (TPIF), is an interesting research topic in material science due to the extreme and complex mode for deformation, the flexibility of the process, and the high forming limits compared to traditional forming processes. Several articles have dealt with experimental study on force measurements for SPIF, like [1] or [2], but only a couple of them focus on sheets with an initial thickness of less than $0.5 \mathrm{~mm}$ ([3]-[6]).

Furthermore, as Gatea et al. [7] highlighted regarding the Fracture Forming Limit Curve (FFLC) in a review, further investigation should be carried out concerning the effect of initial sheet thickness on the tool radius ratio $\left(t_{0} / R\right)$ on the FFLC and whether it is enough to describe FFLC in SPIF. The abovementioned factors and statements inspired this study to conduct experiments on $\mathrm{AlMn} 1 \mathrm{Mg} 1$ sheets with an initial thickness of $0.22 \mathrm{~mm}$ and to run some preliminary numerical simulations with the given process parameters. Former results of this research with the same material explained what kind of control system has been used to execute the tool path on this part [11], and how flat-end tools can improve e.g. the accuracy of the part [12]. Therefore, the aim of this research work is twofold. The primary goal is to apply a non-traditional force monitoring to AlMn1Mg1 foils. The secondary goal is to experimentally validate the main process parameters on sheets thinner than $0.5 \mathrm{~mm}$. The first part of this paper focuses on the material characterisation, introducing a Forming Limit Curve (FLC) measured by the Nakazima test and some numerical simulation results. The second part of this article presents preliminary investigations on the formability of truncated conical shapes with a continuously increasing wall angle as a function of major operating parameters. In addition, forming forces have 


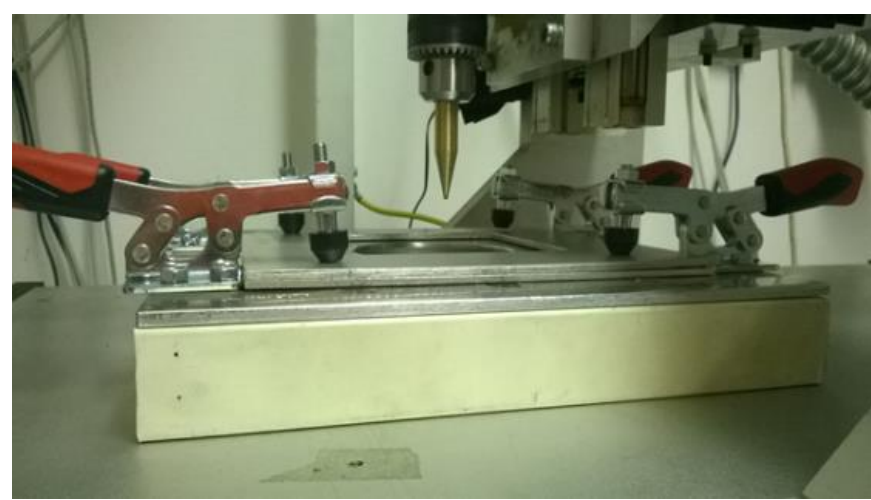

Figure 1. The setup of the experiments.

been investigated experimentally with servomotor acquisitions, and a simplified crack monitoring system is also introduced.

\section{DESCRIPTION OF THE METHOD}

SPIF experiments were carried out on a Rieckhoff Computer Numerical Control (CNC) milling machine. The forming tool and a fast-clamping system are shown in Figure 1. The number of experiments required to determine the forming limit of a sheet can be reduced by using a part geometry with a variable wall angle as explained in [8]. For this reason, a conical frustum with circular generatrix (model generating curve) design was used, as shown in Figure 2.

The $\mathrm{CNC}$ machine control was realised with an open-source real-time control software called LinuxCNC. This control allowed us to send the tool coordinates to a data acquisition program, which also collected the servomotor current data of the zaxis.

The chemical composition of AlMn1Mg1 used for this study is given in Table 1.

The tensile tests were carried out according to EN ISO 68921:2010 standard at room temperature using an INSTRON 5582 universal testing machine. Specimens were cut from sheet in $0^{\circ}$, $45^{\circ}$, and $90^{\circ}$ to a rolling direction. The planar anisotropy values $(r)$ were evaluated from longitudinal and transversal strains measured by the Advanced Video Extensometer (AVE).

The mechanical properties are listed in Table 2. The result of the Erichsen cupping test is $I E=6.79$, and the limiting draw ratio obtained from the cup drawing test according to swift is $L D R=1.7$.

Figure 3 illustrates the FLC and FFLC of the tested sheet, which were constructed from the results of the Nakazima test

Table 1. Chemical composition of the sheet material.

\begin{tabular}{ccccc}
\hline $\mathrm{Al}$ & $\mathrm{Si}$ & $\mathrm{Fe}$ & $\mathrm{Cu}$ & $\mathrm{Mn}$ \\
\hline 96.90 & 0.201 & 0.448 & 0.212 & 0.807 \\
\hline $\mathbf{M g}$ & $\mathrm{Zn}$ & $\mathrm{Cr}$ & $\mathbf{N i}$ & Others \\
\hline 1.260 & 0.071 & 0.022 & 0.006 & 0.073 \\
\hline
\end{tabular}

Table 2. Results of the tensile tests.

\begin{tabular}{cccc}
\hline Direction & $\boldsymbol{R p 0 . 2}$ in $\mathbf{M P a}$ & $\boldsymbol{R m}$ in $\mathbf{M P a}$ & $\mathbf{A g}, \%$ \\
\hline $0^{\circ}$ & 88.3 & 183.0 & 16.44 \\
\hline $45^{\circ}$ & 90.0 & 155.5 & 9.27 \\
\hline $90^{\circ}$ & 86.3 & 170.3 & 12.48 \\
\hline $\mathbf{A 5 0 , \%}$ & $\mathbf{n 5}$ & $\mathbf{r 1 0}$ & \\
\hline 16.88 & 0.297 & 0.554 & \\
\hline 10.45 & 0.266 & 0.580 & \\
\hline 12.98 & 0.268 & 0.594 &
\end{tabular}

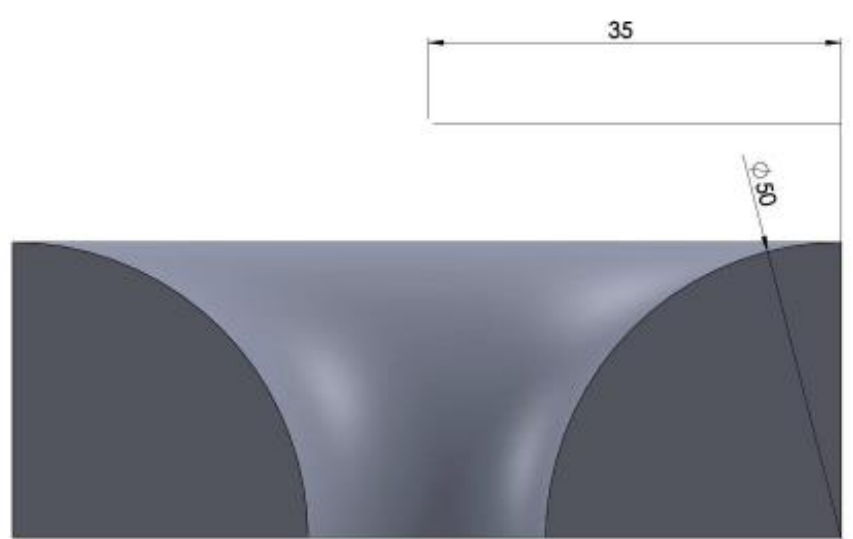

Figure 2. Section view of the test geometry.

using a hemispherical tool with a diameter of $50 \mathrm{~mm}$ and a GOM ARAMIS digital optical measuring system. The FLC was evaluated according to the EN_ISO_12004-2-2009 standard. It is well known from the literature that with SPIF much larger strain values can be achieved compared with a conventional forming process like deep drawing. Therefore, the forming limit in SPIF should be represented by FFLC. The fracture limit strains of the tested sheet were also determined from the Nakazima test using $\varepsilon_{2}-\varepsilon_{1}$ plots of the GOM evaluation system.

It should be noted that this FFLC seems unrealistic as a limit of incremental sheet forming for many reasons. The main argument is that during the Nakazima test, local stretching deformation causes a positive stress triaxiality factor, while with SPIF, the tool generates compressive stress in the sheet metal, which might influence the stress triaxiality in a negative direction and therefore higher strain limits can be achieved. This effect is stronger with Double Point Incremental Forming (DPIF) where a compressive load caused by tools is more significant. To realise this enhanced process, two Parallel Kinematic Machines (PKMs) [13] or two industrial robots should be used [14]. In both cases, the synchronisation of the two tools have to be solved. However, the same results can be achieved with one industrial robot, a Cframe, a linear actuator, and a mechanical copying device [15].

More realistic values for limit strains can be found in the existent literature. At plane strain $\left(\varepsilon_{2}=0\right)$, the limit strain $\left(\varepsilon_{1}=F L D_{0}\right)$ reaches 2.3 for AA1050-O (Filice et al., [16]), 0.84 for AA6114-T4, while 3.0 for AA3003-O (Micari [17]). These values show that significant scatter is among the empirical values.

Applying the classic equation $t_{f}=t_{0} \cdot \sin \left(90^{\circ}-\phi\right)$ (where $t_{f}$ and $t_{0}$ are final and initial thicknesses, and $\phi$ is the wall angle), it can

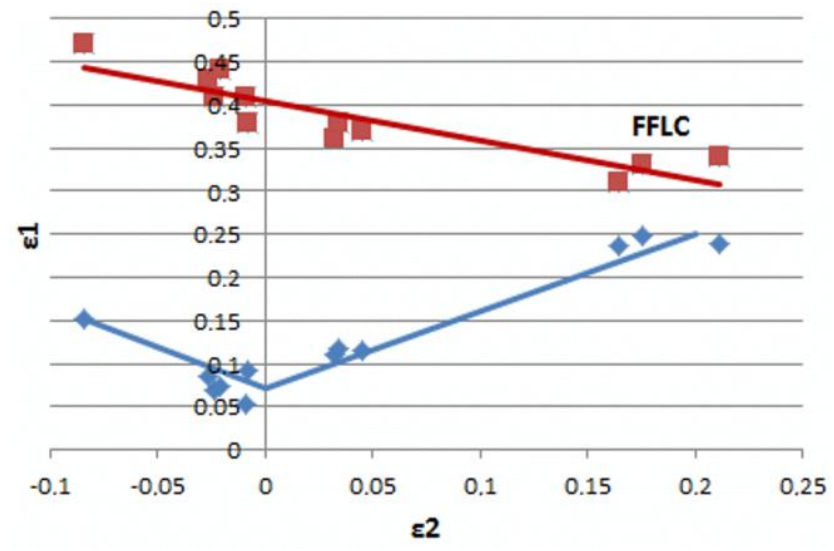

Figure 3. Forming and FFLC. 


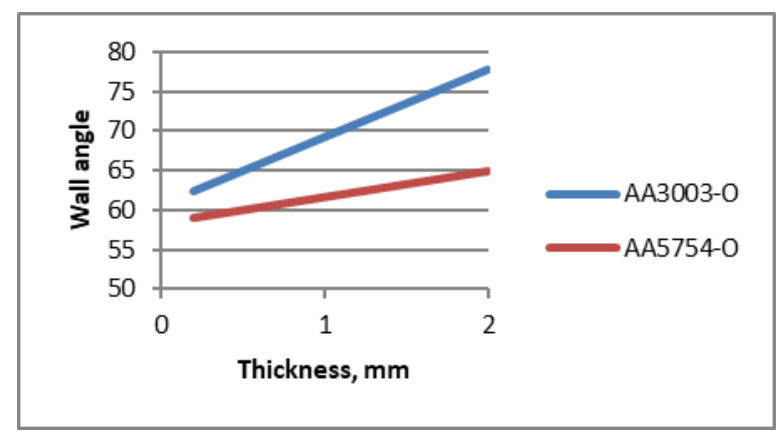

Figure 4. Wall angle vs. sheet thickness.

be calculated that if $\phi=60^{\circ}$, then the logarithmic thickness reduction strain $\left(F L D_{0}\right)$ is 0.9 , and if $\phi=70^{\circ}$, then $F L D_{0}=1.08$.

Figure 4 shows that the lower alloy content of AA3003 enables higher wall angle limits than AA5754, with a $3.5 \% \mathrm{Mg}$ content.

The initial wall thickness influences the limit strain; for example, Kim et al. [18] showed that if thickness decreases from $0.5 \mathrm{~mm}$ to $0.3 \mathrm{~mm}$, the limit strain also decreases by $23 \%$ to $F L D_{0}=0.92$.

Jeswiet et al. [19] elaborated empirical formulae for the calculation of a maximum wall angle for truncated conical specimens.

Equations 1(a) and (b) show the influence of the sheet thickness on the wall angle as a function of material.

$\phi_{\max }=8.5 t_{0}+60.7$ for AA3003-0,

$\phi_{\max }=3.3 t_{0}+58.3$ for AA5754-0

At the same time, it is also visible that as the sheet thickness decreases, the formability also decreases.

The empirical evaluation of local deformations was measured by the GOM ARGUS system [20]. This technique uses a regular mesh on the surface of blank material. After forming process, the local deformations are calculated using ARGUS software. The results from the ARGUS system provide full-field information about the major-minor strain, the thickness reduction, and the geometric parameters of the sheet metal part.

\section{NUMERICAL SIMULATIONS}

The effects of process factors considered as input parameters, such as the tool diameter, incremental depth, and forming speed, were investigated using Finite Element Method (FEM) approaches. In [31], Gál and Lukács gave an overview of the parameters of the high-strength aluminium cold-forming simulations. Great advances in FEM have been related in the literature in terms of predicting the influence of parameters and variables involved in SPIF for the evolution of the process. Examples of explicit [21]-[23] and implicit [24] solutions can also be found in publications. In [23], we also find a comparison of three yield functions.

For analysing the process by FEM, it is necessary to know the plastic behaviour of the material when it is subjected to severe deformations. The determination of the true stress - the true strain curve, which describes the strain hardening of materials (even in the post-necking period) - can be realised experimentally e.g. by the Watts-Fords test or by the extrapolation of the true stress and true strain data of the linear period recorded from the tensile tests. Usually, typical functions like Swift, Voce, Hollomon, Ludwik, Hockett-Sherby, or the proper combination thereof are suitable for the approximation

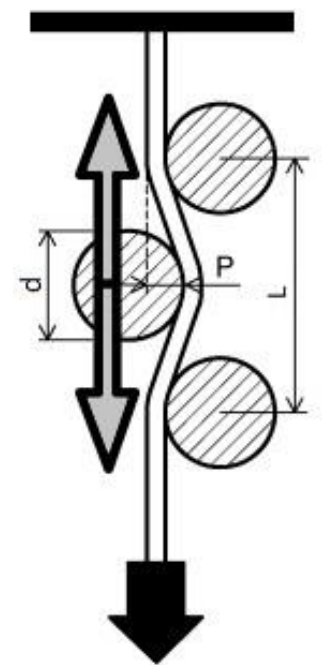

Figure 5. CBT setup with three rolls.

of the post-necking period of the yield curve. Other, similar functions are also used, such as Johnson-Cook's, but some terms that consider the test velocity and temperature are also introduced. Specific methods for determining the material behaviour model can also be taken into consideration, such as photographic techniques (Digital Image Correlation [DIC]) or reverse engineering methodologies [25].

In [26], a comprehensive methodology with two developed analytical models for a multi-stage deformation pass design was proposed. The models were compared with Finite Element Analysis (FEA) and experimental tests concerning the evaluation of the process formability of the final part and thickness strain distributions.

Publication [28] presented the process of the FEA of producing the truncated pyramid parts of AA1100 sheets with a thickness of $1 \mathrm{~mm}$ by SPIF. The tools of the experiments are similar to those used by us. The article gives an explicit solution to the simulation of SPIF by ANSYS (a Finite element analysis software). The authors prepared a geometric model of four parts: the forming tool, the blank, the blank holder, and fixture by using different solid and elastic elements offered by the software. A permanent Coulomb friction of 0.04 was used in the simulations, and the researchers analysed the effects of altering the tool diameter and the incremental depth on the final thickness of the part, von Mises stresses and strains. It was revealed that the maximum stresses occur at the contact region between the forming tool and sheet during deformation, and the increase in the forming tool diameter results in a decrease in the von Mises stresses and an increase in the formed thickness of the workpiece. They found that small stepover values are preferred for increasing the formability and for reducing the forminginduced stresses.

The prediction of the occurrence of fracture is a significant impediment in the adoption of Incremental Sheet Forming (ISF) technologies in industry. Well-developed approaches that study the mechanics of ISF technologies can be found, such as those in [29] and [30].

Emmens and van den Boogaard [32] studied the aspects of incremental forming (the effects of speed and bending angle) in Continuous Bending under Tension (CBT) tests (see Figure 5) and claimed that material thickness had only a minor effect. However, foils (like in our specific case) have not been examined. 


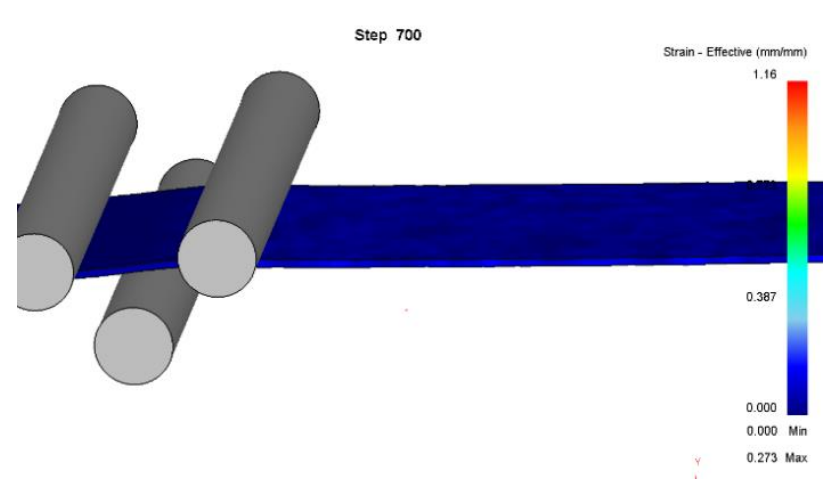

Figure 6. Strain distribution on the effective part of the specimen model.

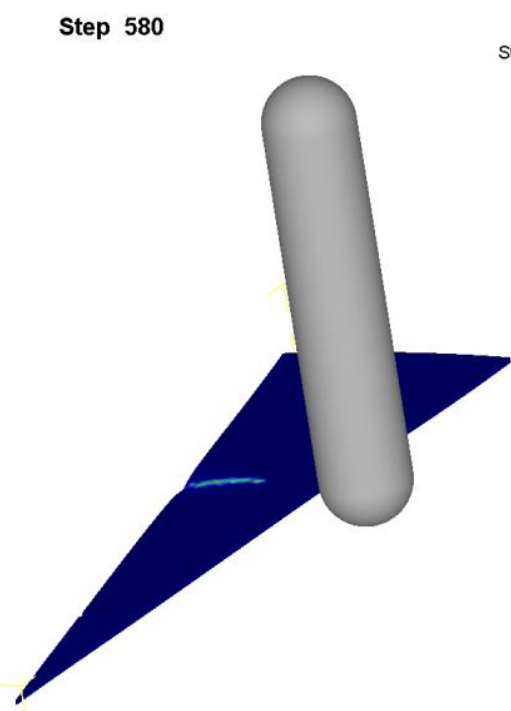

Strain - Effective $(\mathrm{mm} / \mathrm{mm})$ 0.400

0.267

0.133

0.000

$0.00000819 \mathrm{Min}$

$0.413 \operatorname{Max}$

Figure 7. Simulation of the first forming contour.

This is one of the reasons why we considered to model the experimental conditions (up-down speed: $66.7 \mathrm{~mm} / \mathrm{s}$, up-down stroke: max. $140 \mathrm{~mm}$, pulling speed $0.15 \mathrm{~mm} / \mathrm{s}$, pulling distance max. $160 \mathrm{~mm}$, roll diameter: $d=2.381 \mathrm{~mm}$, roll distance: $L=5.56 \mathrm{~mm}$, depth setting: $P=0.094 \mathrm{~mm}$ ) in DEFORM. The same specimen geometry was used by modelling the quarter of the effective part and applying a simple clamping of the sheet. After five hours of calculation, a similar strain distribution appeared (see Figure 6) as in [32].

This confirms the assumption that the same phenomena can be observed with thinner sheets too.

The forming of an AA6061 sheet with a thickness of $1 \mathrm{~mm}$ to a conical shape using SPIF is presented in [27]. This type of aluminium alloy is primarily an $\mathrm{Al}-\mathrm{Mg}$-Si-based precipitationhardened alloy commonly used in aerospace and automotive

Table 3. Process parameters and results.

\begin{tabular}{ccclcc}
\hline $\begin{array}{c}\text { Exec. } \\
\text { order }\end{array}$ & $\begin{array}{c}\boldsymbol{F} \text { in } \\
\mathbf{m m} / \mathbf{m i n}\end{array}$ & $\begin{array}{c}\Delta \boldsymbol{z} \text { in } \\
\mathbf{m m}\end{array}$ & $\begin{array}{l}\boldsymbol{d} \text { in } \\
\mathbf{m m}\end{array}$ & Lubricant & $\begin{array}{c}\boldsymbol{-} \mathbf{z}_{\text {frac. in }} \\
\mathbf{m m}\end{array}$ \\
\hline 1. & 500 & 0.1 & 2.381 & 1 & 22.32 \\
\hline 5. & 500 & 0.3 & 4 & 2 & 20.16 \\
\hline 9. & 500 & 0.5 & 6 & 3 & 19.60 \\
\hline 4. & 1750 & 0.1 & 4 & 3 & 19.81 \\
\hline 8. & 1750 & 0.3 & 6 & 1 & 19.93 \\
\hline 3. & 1750 & 0.5 & 2.381 & 2 & 20.01 \\
\hline 7. & 3000 & 0.1 & 6 & 2 & 18.95 \\
\hline 2. & 3000 & 0.3 & 2.381 & 3 & 20.01 \\
\hline 6. & 3000 & 0.5 & 4 & 1 & 20.10 \\
\hline
\end{tabular}

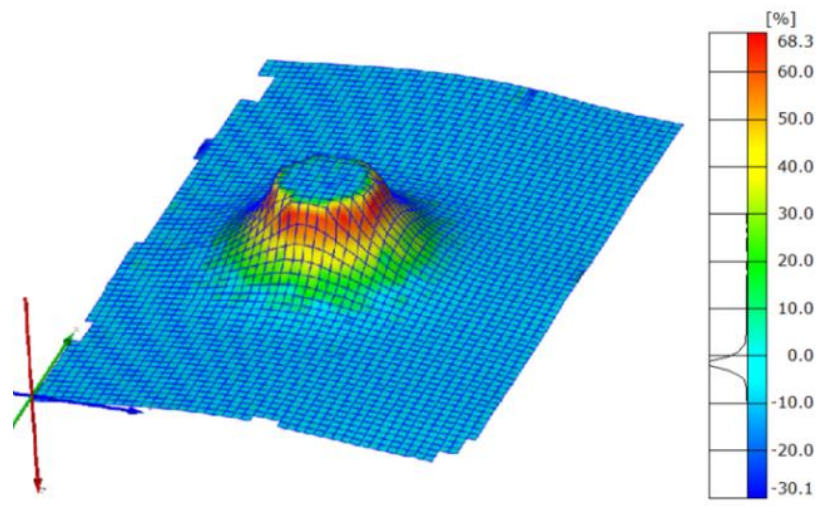

Figure 8. Thickness reduction of the first part.

industry due to its high strength. The maximum formability achieved in AA6061 aluminium alloy was found in the range of $12 \%$ to $34 \%$ with traditional forming processes. To further enhance the formability, the authors performed SPIF experiments; used the Digital Image Correlation (DIC) technique to measure the major and minor strains; and compared the results with FEM results. The contact area (between blank and tool) in this process is very small and localised, which requires a very fine mesh size. By lowering the mesh size, the variation in strain decreased, and smooth surfaces were observed; however, the simulation could not be completed successfully due to limitations in computational capabilities. Therefore, a relatively coarse mesh size of $1 \mathrm{~mm}$ was used to complete the SPIF simulation successfully.

Using traditional solid elements in the pre-calculations (see Figure 7), a simulation time of several weeks has been predicted for us to form a single part, so we decided to stick to experiments with real-time monitoring enhancements.

\section{RESULTS OF THE EXPERIMENTS AND DISCUSSION}

Table 3. shows the process parameters ( $F$ : forming speed, $\triangle Z$ : incremental depth, $d$ : tool diameter, and Lubricant number) applied in the Design of Experiments (DOE, using an L9 orthogonal array of Taguchi) and the examined output parameter. The z coordinate is where fraction occurred on the formed part (-zfrac.). Lubricant number 1 corresponds to a lubricant with Sommerfeld number $S=17.6$, number 2 corresponds to $S=33.4$, and number 3 corresponds to $S=58.4$.

$Z$ axis loads were obtained to monitor the necking and fracture, as in [9]. Figure 8 shows the thickness reduction of the first formed part (from the GOM ARGUS system), while Figure 9 shows the result of the forming, also indicating the fracture caused by necking.

By using the data of the motor and the drive train, the force applied by the axle as a function of the motor current is the following equation:

$$
F_{z-\text { current }}=\frac{2 \pi}{h} \cdot i_{s} \cdot\left(k_{M} \cdot I-M_{R}\right)
$$

where:

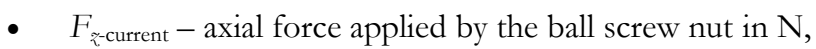

- $\quad b$ - ball screw pitch in $\mathrm{mm}$,

- $i_{s}-$ transmission ratio of the belt drive

- $k_{M}-$ motor constant in $\mathrm{mN} \cdot \mathrm{m} / \mathrm{A}$

- $\quad I$ - motor current A

- $M_{R}$ - torque loss due to friction in the motor in $\mathrm{mN} \cdot \mathrm{m}$. 


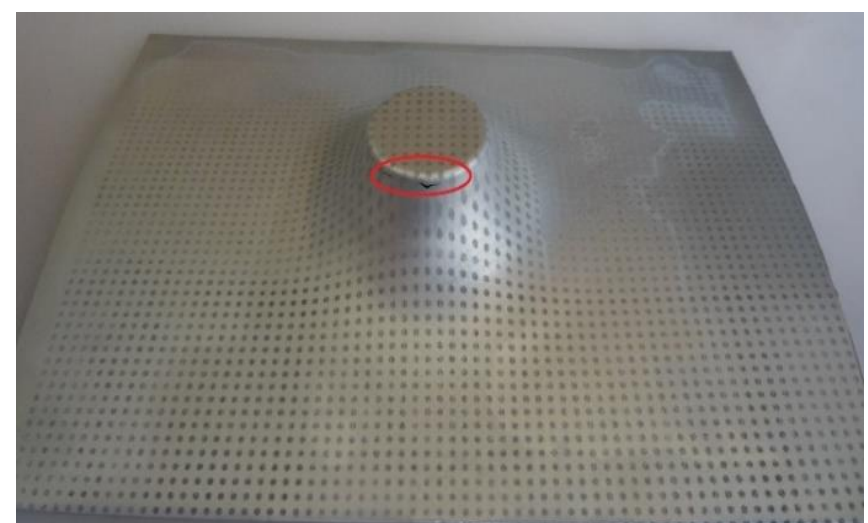

Figure 9. Picture of the first formed part, indicating the fracture.

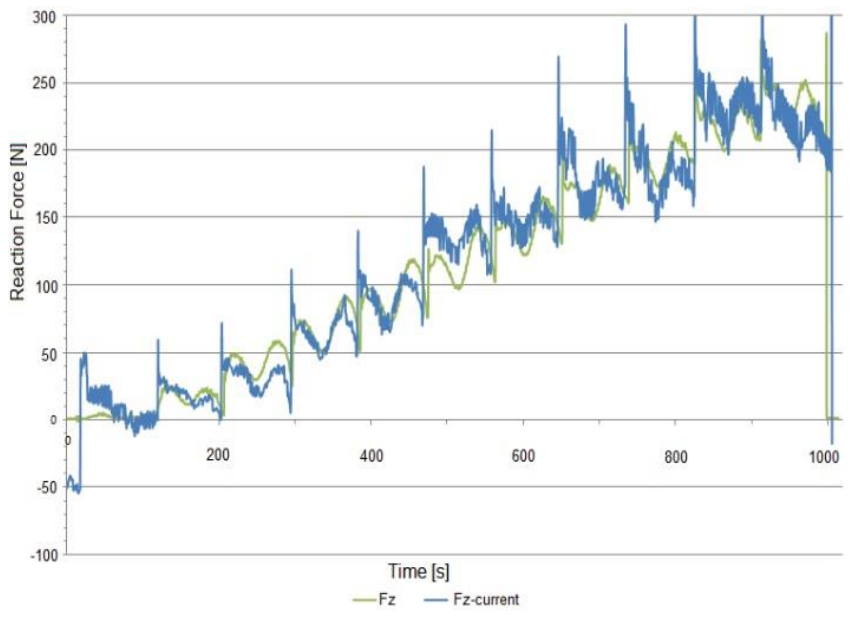

Figure 10. Validation of the measurement concept.

Similar methodology was used by Rauch et al. [10] to evaluate tool loads in a Parallel Kinematic Machine.

Figure 10 shows the validation of the measurement concept, by comparing measurement results from a JR3 Force Cell $\left(F_{z}\right)$ with the calculated forces $\left(F_{x-\text { current }}\right)$ from the motor current measurements.

The reaction force (and the current) increases in the first phase of the forming as the sheet becomes harder to form. Figure 11 shows the results of the first forming, indicating the values of the fracture (the oval mark).

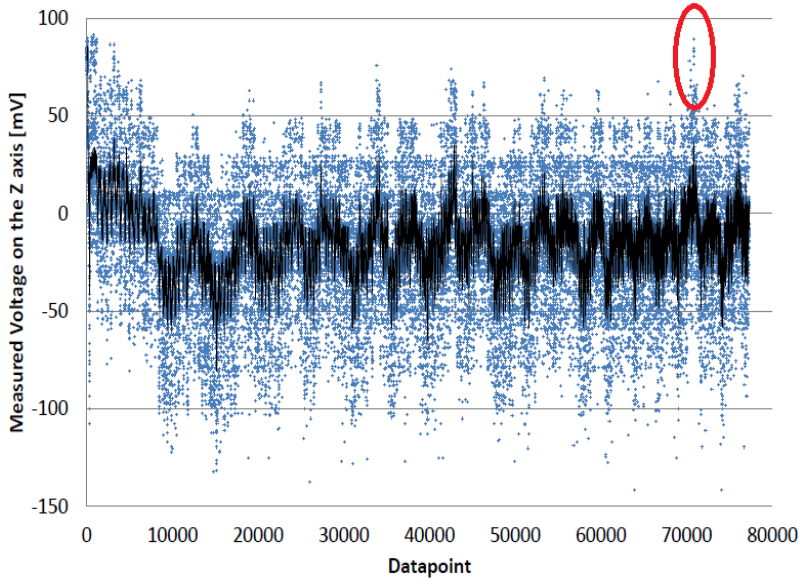

Figure 11. Measured voltage on the $z$ axis with fracture indication [11].

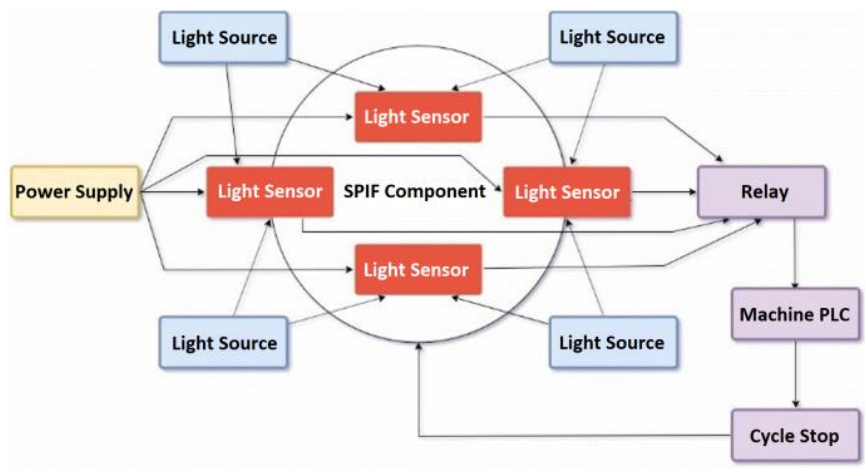

Figure 12. Flowchart of a light sensor-based monitoring system with a cycle stop signal.

A simplified monitoring solution for the crack detection could be the implementation of some light sensors under the sheet (see Figure 12).

Current measurements were realised with a $0.33 \mathrm{Ohm}$ electrical measurement resistance. From Ohm's law, the voltages on the CNC's z axis can be obtained. The peaks in the $F_{z-\text { current }}$ indicate the z-level changes, where the tool pushes the sheet to reach the next depth level up to the fracture. The $F_{z}$ values are pre-filtered in quasi-real time to get a smoother value change.

In case local necking or fracture occurs, the voltage increases around the starting value.

In a simplified case, the supporting rig of the setup would be a dark chamber where the cover is the clamped sheet. Of course, a proper illumination from the forming tool side and an emergency/cycle stop circuit with a trigger signal from the light sensors would be necessary to stop the machine and avoid wasting machining time.

Direct and indirect force monitoring systems are already known, but this new method would be a cost-effective solution with an easier system integration.
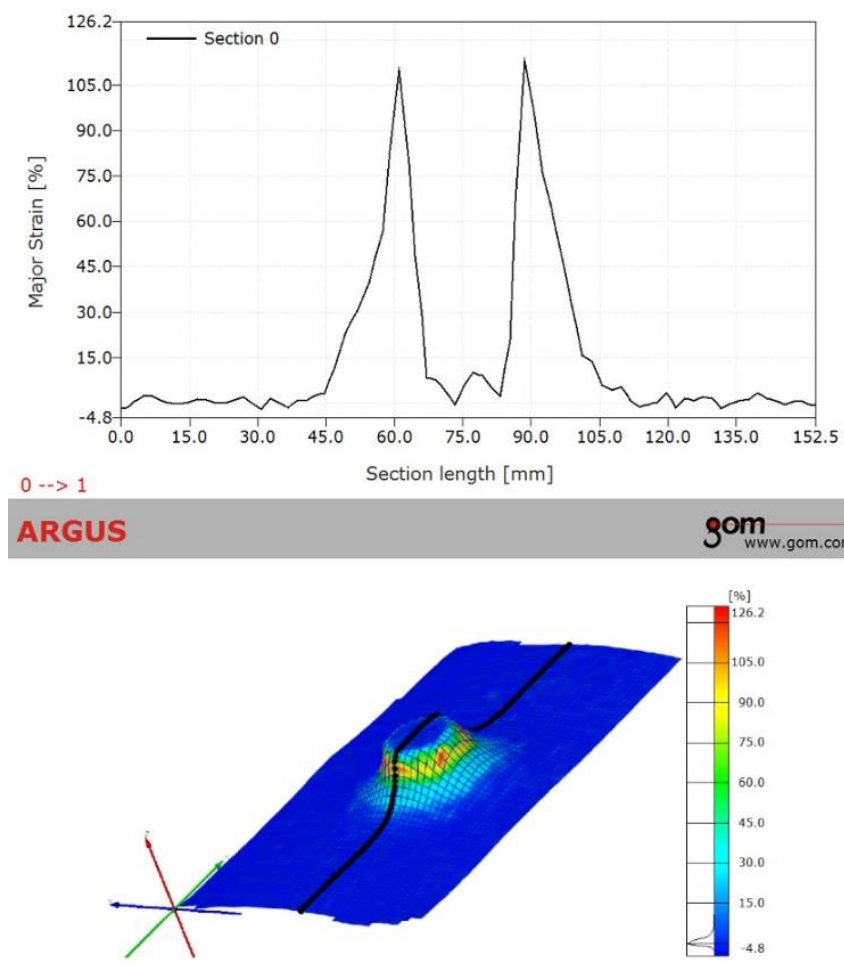

Figure 13. Major strain distribution of the first part in a section. 
Table 4. Results of the roughness measurement.

\begin{tabular}{ccccccc}
\hline & $\begin{array}{c}1^{\text {st }} \text { Measurement in } \\
\boldsymbol{\mu m}\end{array}$ & $\mathbf{2}^{\text {nd }}$ Measurement in & \multicolumn{2}{c}{$\begin{array}{c}\text { Average in } \\
\boldsymbol{\mu m}\end{array}$} \\
\hline $\begin{array}{c}\text { Test } \\
\text { No. }\end{array}$ & $\mathbf{R a}$ & $\mathbf{R z}$ & $\mathbf{R a}$ & $\mathbf{R z}$ & $\mathbf{R a}$ & $\mathbf{R z}$ \\
\hline 1 & 0.95 & 4.10 & 0.73 & 3.80 & 0.84 & 3.95 \\
\hline 2 & 1.58 & 9.40 & 1.47 & 7.00 & 1.53 & 8.20 \\
\hline 3 & 2.55 & 9.70 & 2.58 & 9.50 & 2.57 & 9.60 \\
\hline 4 & 0.46 & 2.70 & 0.47 & 2.70 & 0.46 & 2.70 \\
\hline 5 & 1.10 & 4.60 & 0.98 & 4.60 & 1.04 & 4.60 \\
\hline 6 & 1.65 & 6.70 & 1.53 & 6.00 & 1.59 & 6.35 \\
\hline 7 & 0.28 & 1.80 & 0.31 & 1.80 & 0.30 & 1.80 \\
\hline 8 & 0.45 & 2.80 & 0.50 & 2.90 & 0.48 & 2.85 \\
\hline 9 & 1.50 & 8.10 & 1.22 & 5.00 & 1.36 & 6.55 \\
\hline
\end{tabular}

The major strain distribution in a dedicated section of the same part can be seen in Figure 13. The major strain increased up to $126 \%(1.26)$ in the area of the fracture. Similar phenomena occur with thicker sheets.

This value is similar to that cited from the literature. As it shown in Table 3, the z coordinate, where the fracture occurred on the formed part (-zfrac.), is about $20 \mathrm{~mm}$. Using the part dimensions from Figure 2, the final wall angle can be calculated, giving a value of $78.46^{\circ}$. This is higher than the published wall angle values of regular truncated conic shape, which is used as reference geometry for evaluating the limit strains.

Roughness measurements (see Table 4) were also carried out on the inner wall of the formed parts to compare the results of the different forming tests.

It shows that the best surface roughness can be achieved with the fastest tool movement by using the smallest incremental depth and the biggest forming tool. However, according to the previous table, this combination gives the worst result regarding the forming depth (formability).

To summarise the results of the experiments, an interaction plot of the factors for - frrac. is given in Figure 14.

Experimental results showed that the tool diameter has the primary influence on the forming depth in the case of SPIF on AlMn1Mg1 sheets with an initial thickness of $0.22 \mathrm{~mm}$, which reflects the importance of the $t_{0} / \mathrm{R}$ (initial sheet thickness-to-tool radius) ratio. The second factor in the line of the influencing parameters is the lubrication (with respect to the Sommerfeld

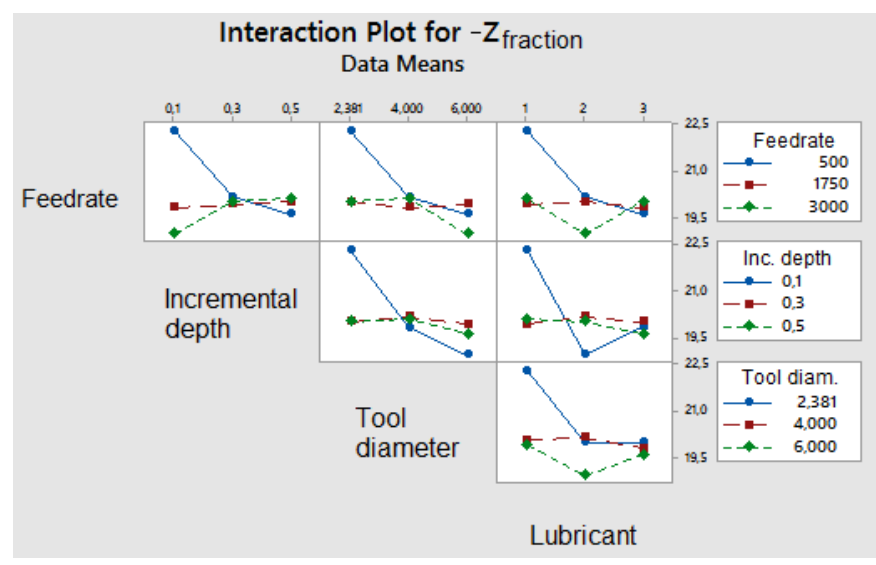

Figure 14. Interaction of the factors for $-Z$ fraction
Table 5. Correlation matrix of the parameters.

\begin{tabular}{c|ccccc}
\hline & $\boldsymbol{F}$ & $\boldsymbol{\Delta z}$ & $\boldsymbol{d}$ & Lubr. & $-\boldsymbol{Z}_{\text {frac. }}$ \\
\hline $\boldsymbol{F}$ & 1 & & & & \\
\hline $\boldsymbol{\Delta z}$ & 0.130 & 1 & & & \\
\hline $\boldsymbol{d}$ & 0.126 & 0.126 & 1 & & \\
\hline Lubr. & -0.130 & -0.130 & -0.126 & 1 & 1 \\
\hline$-\boldsymbol{Z}_{\text {frac. }}$ & -0.574 & -0.385 & -0.661 & 0.564 & 1 \\
\hline
\end{tabular}

number), which is followed by the feed rate and the incremental depth.

Further analysis can be carried out by correlation matrix of parameters, which is displayed on Table 5. Therefore, it follows that the highest correlation index is between the tool diameter and forming depth, and the negative sign indicates that the lower the diameter, the higher the depth. This finding supports the hypothesis that compressing stresses play a key role in the increased formability of SPIF, as a smaller diameter induces compressive stresses more effectively on the surface of the sheet.

Second highest indices can be regarded to feed rate and lubrication, but the effect of $\Delta_{z}$ incremental depth is less significant. This ranking is in good agreement with the conclusions derived from Figure 14.

In case we analyse the tool diameter and feed rate by multiple regression, then Equation (3) gives a simple form to calculate the depth where fracture occurs:

$-Z_{\text {frac. }}=22.8-0.42 \cdot d-0.0005 \cdot F$.

The coefficient of regression is 0.826 , which is acceptable for the further estimation of forming depth if similar geometry and the same sheet metal are used.

\section{CONCLUSIONS}

In this paper, the characterisation of AlMn1Mg1 and SPIF of the same material with an initial thickness of $0.22 \mathrm{~mm}$ have been conducted, applied by a DOE, using a L9 orthogonal array of Taguchi.

Initial numerical simulations gave an unacceptable computing time in the case of SPIF, but the CBT simulations (as an approximate model for incremental sheet forming) gave similar results for the examined foil, as in other documented cases, using thicker sheets. The monitoring of servo-motor currents allowed the estimation of the forming forces, and a new crack monitoring method based on light sensors was also given. All results regarding the estimation of fractures caused by necking are consonant with the results obtained in the SPIF of thicker sheets.

\section{ACKNOWLEDGEMENT}

This research has been supported by the ED_18-2-2018-0006 grant on 'Research on Prime Exploitation of the Potential Provided by the Industrial Digitalisation'. The research in this paper was (partially) supported by the European Commission through the H2020 project EPIC (https://www.centre-epic.eu/) under grant No. 739592.

The research presented in this paper was also carried out as part of the EFOP-3.6.2-16-2017-00016 project in the framework of the New Széchenyi Plan. The completion of this project is 
funded by the European Union and co-financed by the European Social Fund.

The support provided by Viktor Gál, T. Győgér, and Sz. Szalai in the simulations/experiments is also greatly acknowledged.

\section{REFERENCES}

[1] J. Duflou, Y. Tunçkol, A. Szekeres, P. Vanherck, Experimenta Study on Force Measurements for Single Point Incremental Forming, Journal of Materials Processing Technology 189(1-3) (2007) pp. 65-72.

[2] I. Bagudanch, G. Centeno, C. Vallellano, M. L. Garcia-Romeu, Forming Force in Single Point Incremental Forming under Different Bending Conditions, Procedia Engineering 63 (2013) pp. 354-360.

[3] S. Thibaud, R. Ben Hmida, F. Richard, P. Malécot, A Fully Parametric Toolbox for the Simulation of Single Point Incremental Sheet Forming Process: Numerical Feasibility and Experimental Validation, Simulation Modelling Practice and Theory 29 (2012) pp. 32-43.

[4] R. Ben Hmida, S. Thibaud, A. Gilbin, F. Richard, Influence of the Initial Grain Size in Single Point Incremental Forming Process for Thin Sheets Metal and Microparts: Experimental Investigations, Materials \& Design 45 (2013) pp. 155-165.

[5] T. Obikawa, S. Satou, T. Hakutani, Dieless Incremental MicroForming of Miniature Shell Objects of Aluminum Foils, International Journal of Machine Tools and Manufacture 49(1213) (2009) pp. 906-915.

[6] T. Sekine, T. Obikawa, Micro Incremental Forming Characteristics of Stainless Foil, Key Engineering Materials 447448 (2010) pp. 346-350.

[7] S. Gatea, H. Ou, G. McCartney, Review on the Influence of Process Parameters in Incremental Sheet Forming, The International Journal of Advanced Manufacturing Technology (2016) pp. 1-21.

[8] G. Hussain, L. Gao, A Novel Method to Test the Thinning Limit of Sheet Metal in Negative Incremental Forming, International Journal of Machine Tools and Manufacture 47 (2007) pp. 419-435.

[9] G. Ambrogio, L. Filice, F. Micari, A Force Measuring Based Strategy for Failure Prevention in Incremental Forming, Journal of Materials Processing Technology 177(1) (2006) pp. 413-416.

[10] M. Rauch, J. Y. Hascoet, J. C. Hamann, Y. Plenel, Tool Path Programming Optimization for Incremental Sheet Forming Applications, Computer-Aided Design 41(12) (2009) pp. 877-885.

[11] I. Paniti, Zs. J. Viharos, Fracture Diagnostics for Single Point Incremental Forming of Thin Aluminum Alloy Foils, Proc. of the $15^{\text {th }}$ IMEKO TC10 Workshop on Technical Diagnostics in CyberPhysical Era, 6-7 June 2017, Budapest, Hungary, pp. 34-38.

[12] S. M. Najm, I. Paniti, Experimental Investigation on the Single Point Incremental Forming of AlMn1Mg1 Foils Using Flat End Tools, IOP Conference Series: Materials Science and Engineering 448(1) (2018) p. 012032.

[13] C. F. Johnson, V. S. Kiridena, F. Ren, Z. C. Xia, Ford Global Technologies LLC: System and Method for Incrementally Forming a Workpiece, U.S. Patent 8,322,176, 2012.

[14] H. Meier, C. Magnus, V. Smukala, Impact of Superimposed Pressure on Dieless Incremental Sheet Metal Forming with Two Moving Tools, Cirp Annals 60(1) (2011) pp. 327-330.

[15] I. Paniti, J. Somlo, Device for Two Sided Incremental Sheet Forming, EU Patent EP2505279A1, 2011.
[16] L. Filice, L. Fratini, F. Micari, Analysis of Material Formability in Incremental Forming, CIRP Annals 51(1) (2002) pp. 199-202.

[17] F. Micari, Single-Point Incremental Forming: Recent Results, Seminar on Incremental Forming, [CD-ROM] Cambridge University, 22 October 2004.

[18] T. J. Kim, D. Y. Yang, Improvement of Formability for the Incremental Sheet Metal Forming Process, International Journal of Mechanical Sciences 42(7) (2000) pp. 1271-1286.

[19] J. Jeswiet, E. Hagan, A. Szekeres, Forming Parameters for Incremental Forming of Aluminum Sheet Metal, IMECHE Part B. J. of Engineering Manufacture 216(10) (2002) pp. 1367-1371.

[20] https://www.gom.com/metrology-systems/argus.html [Online].

[21] G. Ambrogio, L. Filice, F. Gagliardi, Improving Industrial Suitability of Incremental Sheet Forming Process, The International Journal of Advanced Manufacturing Technology 58 (2012) pp. 941-947.

[22] K. Al-Ghamdi, G. Hussain, The Pillowing Tendency of Materials in Single Point Incremental Forming: Experimental and Finite Element Analyses, Proc. of the Institution of Mechanical Engineers, Part B: Journal of Engineering Manufacture 229 (2015) pp. 744-753.

[23] R. Esmaeilpour, H. Kim, T. Park, F. Pourboghrat, B. Mohamm, Comparison of 3D Yield Functions for Finite Element Simulation of Single Point Incremental Forming (SPIF) of Aluminum 7075, International Journal of Mechanical Sciences 133 (2017) pp. 544554.

[24] M. B. Silva, M. Skjoedt, A. G. Atkins, N. Bay, P. A. F. Martins, Single-Point Incremental Forming and Formability-Failure Diagrams, Journal of Strain Analysis for Engineering Design 43 (2008) pp. 15-35.

[25] J. A. Naranjo, V. Miguel, A. Martínez, J. Coello, M. C. Manjabacas, Evaluation of the Formability and Dimensional Accuracy Improvement of Ti6Al4V in Warm SPIF Processes, Metals 9(3) (2019) p. 272.

[26] Z. Liu, W. J. T. Daniel, Y. Li, S. Liu, P. A. Meehana, Multi-Pass Deformation Design for Incremental Sheet Forming: Analytical Modeling, Finite Element Analysis and Experimental Validation, Journal of Materials Processing Technology 214 (2014) pp. 620634.

[27] V. K. Barnwal, S. Chakrabarty, A. Tewari, K. Narasimhan, S. K. Mishra, Forming Behavior and Microstructural Evolution during Single Point Incremental Forming Process of AA-6061 Aluminum Alloy Sheet, The International Journal of Advanced Manufacturing Technology 95 (2018) pp. 921-935.

[28] S. N. B. Oliaei, M. Eivazzadeh, S. Dadvandipour, Finite Element Modeling of Incremental Sheet Metal Forming of Aluminum Alloy Al 1100, International Scientific Congress Machines, Technologies, Materials 4 (2017) pp. 254-257.

[29] R. Malhotra, L. Xue, T. Belytschko, J. Cao, Mechanics of Fracture in Single Point Incremental Forming, Journal of Materials Processing Technology 212 (2012) pp. 1573-1590.

[30] K. Jackson, J. Allwood, The Mechanics of Incremental Sheet Forming, Journal of Materials Processing Technology 209 (2009) pp. 1158-1174.

[31] V. Gál, Zs. Lukács, Numerical Modelling of Forming High Strength Aluminium, IOP Conference Series: Materials Science and Engineering, 448(1) (2018) p. 012025.

[32] W. C. Emmens, A. H. van den Boogaard, Incremental Forming by Continuous Bending under Tension - An Experimental Investigation, Journal of Materials Processing Technology 209(14) (2009) pp. 5456-5463. 